\title{
A experiência religiosa pós-moderna e o fenômeno da aceleração em comparação com as temporalidades pré-moderna e moderna
}

\author{
Religious experience in post modernity and the phenomena of acceleration \\ in comparison with pre-modern and modern temporalities
}

Helmut Renders*

\begin{abstract}
Resumo
A modernidade tardia é caracterizada por processos da aceleração tecnológica, das mudanças sociais e do ritmo de vida. Estas transformações das estruturas temporais levam não somente a uma reestruturação da vida cotidiana profissional e privada, das estruturas econômicas e das políticas públicas, mas, também da vida e experiência religiosa. $\mathrm{O}$ artigo parte da compreensão de uma dinâmica interação entre a experiência religiosa e seu respectivo contexto temporal. Para isso compara tipos de experiência religiosa com características das temporalidades da antiguidade, modernidade e modernidade tardia. $\mathrm{Na}$ antiguidade favoreciam-se experiências religiosas capaz de lidar com a ordem imutável de todas as coisas, por exemplo, a abnegação. Na modernidade popularizaram-se metáforas religiosas processuais que ainda abrangiam todo o ciclo da vida em perspectiva pessoal, porém, ainda comunitária, como é o caso da categoria "ordo salutis" ou da metáfora "caminho da salvação". Já ao processo da aceleração do tempo na modernidade tardia parece corresponder a ênfase em experiências instantâneas, e de plenitudes emocionalmente sentidas, como é o caso de experiências extáticas em geral e do "batismo no Espírito Santo" em especial.
\end{abstract}

Palavras-chave: Experiência religiosa; pós-modernidade; temporalidade; aceleração do tempo; mudanças sócias; ritmo de vida.

\begin{abstract}
Late modernity is characterized by processes of technological acceleration, the acceleration of social changes and the pace of life. These transformations of temporal structures lead not only to a restructuration of work and private everyday life, economic structures and public policies, but also to religious experience. The article begins with the understanding of the dynamic of interaction between religious experiences and its respective temporal contexts. Different kinds of religious experience are related to specific characters of antique, modern and late modern temporality. During Antiquity, religious experiences capable to handle the immutable order of all things, for example, self-denial was favored. In modernity, processional religious metaphors become popular, however still encompassing life as a whole and still in a communitarian and personal perspective, as the creation of the category "ordo salutis" or metaphor "way of salvation". In turn, the process of acceleration of time in late modernity seems to emphasis on instant experiences, a kind of emotionally heartfelt fullness, as is the case of ecstatic experiences in general and the "baptism in the "Holy Spirit" in particular.
\end{abstract}

Keywords: religious experience; post modernity; temporality; acceleration time; social changes; pace of life.

Artigo recebido em 02 de novembro de 2014 e aprovado em 20 de março de 2015.

*Doutor em Ciência da Religião e Professor da Universidade Metodista de São Paulo. País de origem: Brasil. E-mail: helmut.renders@metodista.br 


\section{Introdução}

Parte-se, às vezes, quanto à compreensão da experiência religiosa, da ideia de uma constante antropológica: a forma humana de experimentar o mundo e a si mesmo em relação a ele, basicamente não teria mudado entre a antiguidade e a modernidade tardia. Outros já acham que isso pode ser até o caso, porém, nunca saberemos, porque às formas passadas das experiências religiosas não teríamos mais um acesso direto: entre nós e o passado sempre estaria a hermenêutica. Neste artigo partimos da compreensão do ser humano como um ser aberto que interage com as mudanças ambientais e sociais através de uma contínua construção, desconstrução e reconstrução da sua cultura e da sua forma de se relacionar com ela, do seu estar no mundo. Pretendemos verificar, quanto ao aspecto religioso da cultura, mais especificamente, da religiosa cristã, como o processo da aceleração do tempo (FLUSSER, 1962; ATTALI, 1982; ELIAS, 1998; PELBART, 1998; ROSA, 2005) influencia é modifica as condições da experiência religiosa comunmente ensinada e aceita como padrão (GLEICK, 1999; GARCIA, [s.d]; ROSA, 2013). Isso, por sua vez, baseia-se na hipótese que as transformações das estruturas temporais do cotidiano resultam em reestruturações da vida, inclusive da vida religiosa, do processo de formação da identidade e subjetividade religiosa, da relação do ser humano com o mundo e da sua percepção do processo da história e da sua inserção no mesmo. 


\section{Experiência religiosa na antiguidade e pré-modernidade: os sacramentos e a transmissão da fé de geração a geração}

"Andai com sabedoria para com os que estão de fora, remindo o tempo". (Colossenses 4.5, segunda a Bíblia Almeida, Revisada e Corrigida).

\subsection{A temporalidade da antiguidade e época medieval}

A citação de Colossenses 4.5 mostra a necessidade de "ler os sinais do tempo" na igreja primitiva. De fato, representava esse discernimento temporal uma revolta contra os aspectos sociais da temporalidade dominante da sua época, reclamando o kairós em meio de um éon que se apresentáva com "eterno" e imutável. A temporalidade pré-moderna dominante partiu de uma cosmovisão que entendeu o universo e as estruturas da vida, inclusive, da vida religiosa, dentro dos ciclos da natureza, como estável e, assim, previsível ${ }^{1}$. A compreensão da inalterabilidade do cosmo nasce de uma necessidade existencial, não de um exercício racional. Nesta perspectiva, garante e promove a vida aquele que observa as regras do passado e aceita o presente como ele é (ROSA, 2013, p. 20-22). ${ }^{2}$ Possíveis mudanças vão além desta imutável realidade e são literalmente localizados no transcendente. A felicidade é a capacidade de não enfrentar o que não pode ser modificado (escola filosófica do estoismo) e consequentemente são na antiguidade os heróis ou parâmetros da fé, os[as] mártires, e na época, medieval, os[as] místicos[as]. Os[As] mártires testemunham a fé e sofrem as consequências no embate entre instituições que se entendem como eternas e os adeptos da nova crença como ateus. Os[As] místicos[as] entram em cena quando em outra época agora a própria instituição da igreja, passa por uma profunda crise e com ela a ideia da igreja como sacramento. Isso ocorre na transição da Antiguidade para a época Medieval, da época Medieval para a Modernidade e da Modernidade para a Modernidade tardia, porém sempre sobre condições distintas.

\footnotetext{
${ }^{1}$ Isso deve ser o caso em grande parte também para as cosmologias da América Latina (cf. CARRASCO, 2014). Para o mundo ocidental veja Thomas Kuhn $(1957,2000)$, os primeiros três capítulos ou Adam Frank (2012).

${ }^{2}$ Nesta perspectiva o herético sempre é quem perturba ou desafia a ordem estabelecida.
} 
Em um cosmo imutável Deus também é preferencialmente considerado inalterável. O movedor imóvel da filosofia grega corresponde a esta cosmovisão. 3 Nestas circunstancias pode se enfatizar nas religiões a obediência aos cultos que garantem a sagrada ordem da vida, ou a fé na sagrada ordem da vida que ainda se espera no porvir, também descrito como eternidade que articula um tempo ideal fora do tempo, porém, sem fim. A variável, nesta época de um planeta ainda não superlotada, é o espaço. Consequentemente, descreve-se libertação de circunstâncias imutáveis como migração: o recomeço passa pelo espaço alternativo, na terra ou no céu, não pela alteração das ordens estabelecidas.

\subsection{Características da experiência religiosa na antiguidade e época medieval}

Para relacionar a respectiva temporalidade com a experiência religiosa precisamos favorecer as expressões que se dirigem à grande maioria de pessoas, que se comunicam a esta maioria e que são praticadas por ela. Com isso não valorizamos em seguida experiências religiosas consideradas extraordinárias, reservadas a um grupo menor, eventualmente até consideradas experiências que revelam supostamente mais intimidade com Deus, ou intensidade da fé, como a experiência mística, reservada a poucos santos, normalmente monges. Estas experiências, porém, sendo elas consideradas inatingíveis pela grande maioria das pessoas de uma época, e de um povo, no mesmo momento que elas certamente também não escapam da respectiva temporalidade, também não a representam amplamente. 4

A mais importante forma de mediação ou provocação de experiência religiosa na época medieval são os sacramentos e, dentre eles, na celebração dominical, a eucaristia. O foco está na “... união vital do cristão com Cristo

\footnotetext{
${ }^{3}$ Nos textos bíblicos, a descrição do Deus criador aproxima-se mais a este conceito. Tudo indica, porém, que esta ênfase na divindade não é a mais antiga. Pelo contrário, o testemunho do Deus que liberta da casa da servidão a antecede.

${ }^{4}$ Isso vale para o ideal medieval da união mística, propagada também pela reforma católica durante a época da modernidade.
} 
mediador na Igreja, [...] graça aos sacramentos” (GILBERT, 1999, p. 100). Ela está no centro do culto e representa a presença substancial do divino na vida dos crentes. Desde a missa de Gregório, que reafirma esta ênfase no nono século e que marca a espiritualidade medieval, a mediação sacramental era considerada o único, mas também o caminho suficiente para conhecer a Deus e se manter na sua presença. Esta lógica sacramental, esta capacidade de "mentalizar o sacro" ou o sagrado, pela contemplação, junto a elementos básicos da vida, que assim não deixam de ser outra coisa do que substâncias, esta habilidade de entender a Cristo, relacionado de forma inseparável junto as coisas e, assim, juntando as vidas, marca a época. Ela é tão importante e evidente que até boa parte das experiências extáticas e extraordinárias da união mística acabam sendo vinculadas com a contemplação de elementos da Santa Ceia, transformada em devoção. 5 Em termos temporais, a transmissão sacramental da fé foca na articulação da experiência religiosa das gerações anteriores, de geração em geração. Isso explica também a compreensão da própria igreja como sacramento: instituições tem em primeiro lugar a tarefa, depois das fases carismáticas das origens, de garantir a fiel transmissão de geração em geração. Elas entram em crise quando as mudanças ocorrem com uma velocidade que atinge a alteração das gerações ou, como hoje, quando as transformações nem esperam mais a sucessão de uma nova geração. No momento que cada geração precisa se reencontrar no mundo, cada dia mais diferente ou distante do mundo das gerações anteriores, instituições acabam sendo obsoletas quanto à sua função clássica da transmissão da tradição. ${ }^{6}$

\footnotetext{
${ }^{5}$ A devoção do Sagrado Soração ou a forma mais europeia a São Benedito, o Benedito com o menino Jesus em um pano - em distinção, por exemplo, do Benedito do Rosário dos[as] escravos[as] -, ou ensinam a contemplar os elementos da eucaristia ou são memórias do seu impacto nas biografias dos respectivos santos.

${ }^{6}$ As transições da Antiguidade para a Época Medieval e da Época Medieval para a Modernidade mostram também que, depois de um tempo de desconstrução de instituições, elas resurgem, eventualmente, em um novo formato (o que significa "igreja sempre reformanda" senão uma tentativa de adaptação à nova temporalidade, com sua exigência de mudanças contínuas?).
} 


\title{
2 Experiência religiosa na temporalidade da modernidade: conversão e caminho da salvação como ênfase na apropriação e desenvolvimento pessoal da fé
}

\begin{abstract}
"Até agora houve aparentemente duas grandes formas ou sistemas culturais em busca de garantir a responsividade do mundo: as religiões que permitem um ou mais Deuses "lá fora", e a arte - poesia e especialmente a música -, que, segundo a imaginação dos românticos, acorda o mundo para responder com uma canção" (ROSA, 2013, p 147).
\end{abstract}

A forma como o ser humano se experimenta no mundo mudou com a modernidade de forma profunda. A noção da responsividade, de fazer parte de um universo bem estruturado, com intencionalidade, etc. deu, passo a passo, espaço a noção de um mundo "calado, frio, desinteressado e até repugnante" (ROSA, 2013, p. 146) e de um ser humano desencantado com Deus, com este mundo e consigo, alienado de si e do mundo. Mais uma vez, conjugaram-se uma nova cosmovisão e a temporalidade, com profundo impacto na forma de experimentar religiosamente a vida.

\subsection{A temporalidade da modernidade}

A temporalidade moderna é acompanhada pela revolução copernicana (KUHN, 1957, 2009; KOYRÉ, 1973), a reorientação da cosmovisão do geocentrismo para o heliocentrismo.7 Apesar de representar uma perspectiva radicalmente nova para a época ${ }^{8}$, entendemos hoje que na época o universo ainda visto segundo uma lógica mecânica que partiu do modelo do relógio9. A sensação era de uma novidade radical, porém, ainda calculável. Mesmo que no modelo heliocêntrico a terra se movia, o sol era ainda o centro do universo e a terra, relacionada com este centro, tinha forma firme. Em outras palavras, o cosmo era ainda visto como basicamente estável, um cenário que favoreceu a pesquisa em busca da compreensão dessa nova

\footnotetext{
${ }^{7}$ A primeira previsão exata das posições dos planetas era, porém, do astrônomo alemão Johannes Kepler (1571-1630), evidenciado, depois pelo astrônomo italiano Galileo Galilei (1564 - 1642).

${ }^{8}$ A ideia, porém, já tinha sido desenvolvida pela primeira vez por Aristarco de Samos (310 - 230 a.C.).

${ }^{9}$ A metáfora é atribuída a Isaac Newton, porém, ela já é usada no século 12 (cf. FRANK, 2012). Sem dúvida nenhuma porém, se apropriou dela depois o deismo.
} 
situação e do seu controle. Esta novidade acabou se estendendo à compreensão temporal.

Mudou-se a perspectiva. Se a ênfase temporal da pré-modernidade foi o passado, a temporalidade moderna se concentra no futuro (ROSA, 2013, p. 22-24). Isso articula, em primeiro lugar, uma insatisfação com o passado e o presente, e em segundo lugar, indica o caminho para a sua superação. Isso vale também para o mundo religioso como sistema de ver e se colocar neste mundo. Surge a necessidade de encontrar novas certezas, entre elas, a "certeza da fé". Neste horizonte utópico, a promessa não é mais meramente celestial, mas também terrestre, no inicio menos, ao longo dos séculos mais e mais, inclusive até finalmente prometer ou visualizar - já nas suas releituras seculares - o paraíso ou o reino de mil anos na terra.

Agora, tanto o tempo como o espaço são mutáveis. Apesar de que se projetem ainda novos mundos em lugares de migração, por exemplo, nas colônias, começa-se agora imaginar que o espaço também pode ser modificado. Reforma, transformação e, finalmente, revolução descrevem agora a relação com o espaço terrestre e a sociedade humana, onde agora se pretende "antecipar" o tempo do porvir. Deus é nestas circunstâncias visto de formas muito alternativas: os governantes e as suas instituições reclamam-no para si e, de grau crescente, também as classes subalternas. Às vezes, apresenta-se como cobrador dos pobres e fiador dos ricos, às vezes como promotor de amor, justiça e misericórdia.

\subsection{A experiência religiosa na modernidade}

Transparece na vida religiosa, mais fortemente então, a ideia de construção e colaboração entre Deus e o ser humano, como possibilidade e dever. Discute-se na religião agora não somente o perigo da profanização, mas, também do fanatismo. A profanização - as atitudes que não cabem no templo (fanis) - é criticada por àqueles que pensam o mundo em uma perspectiva teocêntrica; o fanatismo - as atitudes extremas daqueles que pertencem ao templo - é criticado por àqueles que 
pensam o mundo em uma perspectiva mais antropocêntrica. Como na vida particular, o ser humano como individuo precisa agora construir o seu caminho religioso. A possibilidade da escolha e a ênfase na liberdade da fé fazem da conversão condição e início da vida cristã, como confirmam o Catecismo de Heidelberg (1563, perguntas 86 e 87) e a Formula de Concórdia (1577), mesmo que insistam que essa responsabilidade é baseada na experiência da graça de Deus.

A razão para essa grande mudança está novamente relacionada com as mudanças temporais. A partir da modernidade muda o mundo com uma nova velocidade. Cada geração precisa se encontrar em um mundo diferente do mundo dos seus antecessores. Pessoas escolhem agora as suas profissões, seus parceiros de vida, sua religião. Nesta perspectiva, há muitos "novos começos". Consequentemente, qualquer tipo de plenitude é vista como resultado de um processo que abrange uma "vida toda" e "toda a vida". Não se podem favorecer experiências pessoais únicas, mas etapas correlacionadas, que em conjunto visam para frente. A conceituação desse processo e das suas etapas em termos religiosos ocorreu consequentemente no século 18. Refere-se ao ordo salutis na teologia luterana ou ao caminho da salvação na teologia arminiana. Sintetiza-se um processo que inicia com o batismo infantil e vai até o fim da vida. Espera-se não somente perseverança - para justificar a entrada na eternidade ou no tempo pleno e melhor -, mas santidade, perfeição, como sinais de maturidade. Trata-se também de uma articulação teológica onde se procura valorizar o aspecto humano ao lado do aspecto divino, que resultou no debate sobre sinergismo e o papel da graça e das obras na vida cristã. A experiência religiosa nem é mais marcada pela era recepção, contemplação ou devoção, nem pela mera construção. A discussão dessa mudança, porém, causa rupturas e longas discussões. ${ }^{10}$

\footnotetext{
${ }^{10} \mathrm{Na}$ teologia calvinista há a tensão entre a dupla predestinação, que representa um tipo de hiperteocentrismo, e a teologia do batismo e da santa ceia de Zwínglio, e sua abordagem radicalmente humanista. Lembra a discussão sobre sinergismo entre teologia luterana, calvinista e arminiana, e a discussão sobre a justificação imputada e compartilhada..
} 


\section{Experiência religiosa na pós-modernidade: o desejo da plenitude imediata e instantânea em um mundo momentâneo e líquido}

"Por falta de tranquilidade, nossa civilização se transforma numa nova barbárie. Em nenhum outro tempo os ativos, isto é, os intranqüilos, valeram tanto." ${ }^{11}$ Friedrich Nietsche (1988, p. 232 [aforismo 285]).

\subsection{A temporalidade da modernidade tardia}

A temporalidade pós-moderna coincide novamente com uma modificação da cosmovisão. A descoberta que o sol não é o centro da nossa galáxia (1918), e também não o é do universo ${ }^{12}$, a existência de outras galáxias (1920)롤 e as teorias sobre a expansão do universo (1927), radicalizaram a sensação de estar no cosmo do ser humano. ${ }^{14}$ Ser parte de um cosmo composto por cerca de 100 bilhões de galáxias, em movimento, em aceleração, desafiou ainda mais a ideia da humanidade como coroa da criação e objetivo principal da criação do universo.

Se a ênfase temporal da pré-modernidade foi o passado, e da temporalidade moderna o futuro, a pós-modernidade se caracteriza pela ênfase no presente (ROSA, 2013, p. 24-26). Isso resulta em uma perda dupla: por um lado, das tradições, por outro lado, das utopias. A aceleração de todas as coisas confronta o ser humano com a experiência do rápido vencimento da validade de conhecimento tecnológico, da sabedoria cultural e da validade social de comportamentos e atitudes comunitários. Com a perda de tradições perde-se também, ou no mínimo, enfraquece-se, a noção de descendência e da permanência a algo. Já a perda das utopias é efeito colateral da ênfase na inovação. Uma inovação é a estranha combinação de, por um lado, o anúncio do alcance de algo supostamente nunca

\footnotetext{
${ }^{11}$ A tradução é de José Carlos Bruni (2002, p. 34).

12 Pelo astrônomo americano Harlow Shapley (1885-1972).

${ }^{13}$ Pelo astrônomo americano Edwin Powell Hubble (1889-1953).

${ }^{14}$ Os diversos modelos atuais a respeito do fim do universo no big crunch (retraição), big freeze (expansão não invertida leva ao congelamento) ou big rip (grande ruptura) também não contribuem para a ideia de um significado cósmico da humanidade e da vida terrestre. O título Relativistic Cosmology de George F. R Ellis, MAARTENS, Roy Maartens e Malcolm A. H. MacCallum. de 2012 indica o recolocamento do ser humano.
} 
visto, e, por outro lado, de algo com uma provável data de validade. ${ }^{15}$ A inovação é uma utopia realizada e superada num prazo relativamente curto. Não por acaso migra a inovação mais e mais para o campo da estética, sendo a estética muito mais apta de acompanhar ciclos acelerados de novidades, de seis em seis meses, como é o caso da moda, do desenho e do visual. No nível existencial, articula-se esse fenômeno duplo pela reclamação em conjunto que o mundo pós-moderno seria um mundo sem valores e sem utopias.

A relação modificada com o passado e futuro muda também a relação com o espaço. Com a aceleração do tempo diminui o presente, no sentido de um tempo onde o passado já não prevalece mais e o futuro ainda não vale (Agostinho). Este encurtamento do tempo presente é também acompanhado por uma relativização do espaço. Em consequência, Deus eterno perde o seu "espaço" no mundo pósmoderno, o Deus imutável, ou ainda o Deus das longas narrativas das instituições religiosas. Isso ocorreu nos últimos duzentos anos. Já na atual fase dessa aceleração, que nós experimentamos como fragmentação das nossas vidas particulares, o próprio ser humano perde mais e mais espaço no mundo. Ele se não sente mais em casa neste mundo, no mínimo, sente-se incomodado nessa forma de civilização, uma civilização onde os processos da aceleração acabam-se desvinculando dos seus ciclos da vida.

\subsection{A experiência religiosa na modernidade tardia}

Mais uma vez observamos tendências mais amplas, tendências de "moda", caminhos que atraem um número significativo de pessoas e que também apelam a um número ainda maior de pessoas. Os diversos aspectos da nova temporalidade criam ambientes mais densos. A aceleração tecnológica, por exemplo, possibilitou uma comunicação em nível global, quase na hora do acontecimento. Esperamos, na

\footnotetext{
${ }^{15}$ A aceleração dos ciclos da inovação faz que ela se reduz já cada dia a meras inovações estéticas. Assim mostra Reckwitz (2012) que identifica na relação entre criatividade e estética uma das mais importantes aspectos das sociedades pós-modernas. Criatividade é uma categoria paralela a categoria da inovação.
} 
década 70, o tempo necessário para o envio de uma carta e a recepção da resposta em até uma semana. Respondemos hoje e-mails no mesmo dia ou até na mesma hora. Pior: quem não responde com esta velocidade é considerado esquecido, desinteressado ou, no mínimo, deselegante, ou, em outras palavras, uma pessoa que não está à altura dos acontecimentos (em aceleração). Na vida pessoal criou-se então a ideia da satisfação quase instantânea de seus desejos, ideia promovida e explorada pelo mundo de consumo. E como o desejo natural aparentemente não basta, cria-se se permanentemente desejos novos e específicos a serem imediatamente "respondidos" por um produto. Isso conquistou também o campo da religião e da experiência religiosa.

$\mathrm{Na}$ modernidade, a satisfação do desejo religioso era ainda vista como resultado de um caminhar longo, com a expectativa de se aproximar à perfeição somente no final da sua vida. Na pós-modernidade, mudou-se a ênfase na experiência religiosa da plenitude, não só para o início da caminhada religiosa, mas para uma nova densidade, com uma abrangência nunca antes vista. Isso explica, por sua vez, a proximidade estrutural e a diferença social entre a ênfase medieval na união mística e a ênfase na modernidade tardia no batismo no Espírito Santo, como experiências altamente prestigiadas. Ambas as ênfases do encontro com Deus no interior do ser humano - ou de Deus - ocorrem em um momento de transição de épocas nas quais as instituições - que normalmente cuidam da transferência de experiências antigas para as próximas gerações - geralmente não são mais preferencialmente procuradas em busca de respostas às perguntas essenciais. Pelo contrário, fala-se da ampla crise de todas as instituições que compuseram a sociedade moderna. A diferença entre a experiência mística medieval e pósmoderna esta na inversão temporal: na época medieval esperava-se a união mística no final de um longo caminho de esvaziamento, seguida pela iluminação; na modernidade tardia a experiência do batismo pelo Espírito Santo é esperada logo depois do início da iniciação na fé cristã, confissão e batismo. É uma experiência esperada já no presente. Consequentemente, sofre uma universalização. Perde-se a ideia do extraordinário e alega-se agora a sua acessibilidade por cada pessoa, o que se desdobra depois na afirmação do dever de passar por essa experiência religiosa. 
Não ter esta experiência significa literalmente perder tempo por não poder avançar, sinônimo de estagnação e de ficar atrás, se desvincular do ritmo da vida religiosa pós-moderna. Mais corretamente seria dizer que isso significa se desvincular do ritmo da temporalidade pós-moderna e, por sua vez, ter como característica se desvicular dela mesma e do ritmo da vida. Alega Hartmut Rosa que a aceleração social (2013, p. 15-20), como aceleração, técnica (p. 2013, p. 2021), a mudança social (2013, p. 22-26) e do tempo de vida (2013, p. 26-33), criaram um círculo de aceleração na "qual as três categorias acima chamadas [...] tenham formado um sistema de feedback autofortalecente que a si mesmo se lançava, de forma ininterrupta" (2013, p. 42). Entretanto, "as normas temporais se distinguem em um ponto fundamental das normas morais, políticas e religiosas em vigor em outras culturas e outros tempos" (2013, p 111): elas são vistas como naturais - o tempo pertence ao ciclo da natureza e do cosmo, ou seja, o indivíduo se submete ao seu regime, sem noção que é resultado de trabalho cultural.

\section{Excurso: A sobreposição das temporalidades e da busca da experiência religiosa no cotidiano}

Não devemos ignorar outro aspecto da modernidade tardia, o do paralelismo de discursos alternativos, agora não mais como discursos únicos e dominantes mesmo que isso ainda se defenda no campo religioso por um ou outro dos seus representantes. Somos ainda acostumados a representar essas diferenças conceitual, doutrinária ou confessionalmente, enquanto novos movimentos e grupos religiosos já integram esta multiplicidade paralela - inclusive de temporalidades - em suas vivências e propostas religiosas, de forma muito dinâmica e eclética.

Observamos, por exemplo, uma releitura da mediação sacramental, porém, com novos focos e não, necessariamente, como retorno para a reafirmação nova dos sacramentos mais clássicos, como o Batismo e a Santa Ceia, como lugares para experiências religiosas constitutivas. Enquanto leituras teocêntricas e, por 
causa disso, sacramentais do batismo, preferencialmente de crianças, e da ceia, como mediação da presença real do Cristo em substância ou no mínimo consubstancial, aparentemente se comunicam menos em nossa temporalidade acelerada pós-moderna, mesmo assim surgem novas dinâmicas sacramentais.

Em casos como da Igreja Universal do Reino de Deus, essa dinâmica se reflete numa contínua produção de novos artefatos e ritos com funções supostamente sacramentais, como a fogueira santa, o saquinho da trindade, a rosa abençoada, ou a sessão do descarrego etc., etc. Facilmente podemos interpretar essa produção como a busca de atender pessoas que vivem na temporalidade "medieval" e consequentemente procuram instituições-sacramentos e seus “sacramentos" para ter acesso ao sagrado. Neste sentido, é o templo de Salomão da IURD significante para o projeto da igreja, por ser diferente das outras igrejas e por simbolizar o lado institucional do sagrado. Sendo uma igreja nova, ela precisa ter novos meios da graça que a distingue das demais igrejas, sem, porém, poder escapar dos seus aspectos formais: um sacramento requer uma teologia teocêntrica com uma clara distinção entre o sagrado, e não somente o profano, mas também o sagrado e o demoníaco. Parte dessa dependência de formas religiosas estabelecidas é também a durabilidade da sessão de descarrego. Esta prática ritualista e sacramental é uma citação de uma prática de outra religião, a releitura dessa prática e sua integração e ressignificação dentro de um sistema cristão, que é favorecida pela tradição já constituída. Porém, dentro da perspectiva da temporalidade, esse fenômeno somente se reproduz enquanto as pessoas vivem existencialmente na respectiva temporalidade. O templo de Salomão é uma tentativa de materializar simbolicamente a durabilidade da instituição IURD sugerindo "raízes" que vão até além do cristianismo.

Da mesma forma explica-se o aparecimento de garrafinhas com óleo nos "altares" de igrejas protestantes. Por um lado, isso ocorre no momento paralelo da desconstrução dos sacramentos clássicos do batismo e da Santa Ceia. Em termos temporais, representam a rejeição do batismo de criança e a ênfase na celebração da Ceia como mero memorial, a perspectiva antropocêntrica da temporalidade 
moderna com sua ênfase na escolha e na necessidade de construção. Por outro lado, a garrafinha com óleo assumiu um lugar de destaque, inclusive junto a uma resignificação da mesa do senhor ou da mesa de comunhão como “altar”. Esta popular ressignificação transforma um lugar da interação divino-humano em um espaço da mera ação divina. Em outras palavras, abraça a temporalidade prémoderna. A sacralidade do objeto "garafinha de óleo" se revela no momento que alguém quer usar o mesmo sem autorização "sacerdotal” e, por exemplo, quer tirálo do "altar". Isso é negado, por que fora desse lugar o sacramento perde seu significado, por ser desvirtuado do espaço que representa o acesso ao divino. Em termos temporais, porém, representa o retorno de um conceito chave medieval altar - e de uma representação substancial do sagrado - o óleo - uma ênfase na temporalidade pré-moderna, que se sustenta religiosamente por formas mais materiais e institucionais. Não é incomum que encontremos em comunidades que, por um lado enfatizam a fala em línguas estranhas, ou o batismo no espírito, ou seja, experiências estáticas, ao mesmo tempo tenham a garrafinha com o óleo no "altar".

\section{Considerações finais}

No Brasil, convivem cosmovisões pré-modernas, modernas e pós-moderna, e no campo religioso parecem, às vezes, posicionamentos pós-modernos, como um retorno para posicionamentos pré-modernos. ${ }^{16}$ Todas estas formas de "estar no mundo" convergem com formas de experientar o mundo e a vida, inclusive de forma religiosa. Dentro disso, não se nega certa tendência da religiosidade cristã pós-moderna de rejeitar a religiosidade moderna e dialogar com cosmovisões medievais, eventualmente, não muito diferente do projeto da renascença de se inspirar na antiguidade e declarar a época medieval com escura e retrocedida.

\footnotetext{
${ }^{16}$ No cotidiano brasileiro relacionam-se diferentes atitudes diante do tempo com descrições regionais: o[a] paulistano[a] como mestre da aceleração, nunca parada, porém sempre estressado, não perdendo tempo, mas, eventualmente a vida; o[a] baiano como mestre da desaceleração, bem com a vida, porém, meio parado no tempo e espaço. Independente do caráter pré-conceituoso desse tipo de afirmações generalistas, chama a atenção como a atitude do ser humana diante do tempo é considerado significante na tentativa de descrever pessoas na sua essência cultura.
} 
Entretanto, na perspectiva da distinção das temporalidades pré-modernas, modernas e pós-modernas e da aceleração do tempo como fenômeno dinamizante, abre-se também uma perspectiva que não identifica um mero retorno, mas ênfases que reciclam elementos antigos em formas e conteúdos novos, que somente pontualmente tem a ver com o passado medieval ou da reforma católica.

Chamamos a atenção que em geral os resultados dos processos de aceleração do tempo são considerados algo natural:

As normas temporais se distinguem em um ponto crucial das normas morais, políticas e religiosas de outros tempos ou culturas: mesmo que sejam sem dúvida nenhuma também socialmente construídas, elas não são vestidas por um etos. [...] Elas funcionam como fatos puros, leis da natureza, inquestionáveis e indiscutíveis (ROSA, 2013, p. 111).

Nesta perspectiva eles pertenciam a nossa vida moderna e pós-moderna e se deve aprender a lidar como eles e, em ultima instância, se submeter a eles. As sensações de uma esmagadora presença das formas contemporâneas da mediação religiosa, às quais se deve obedecer para não parecer ou desaparecer como instituição ou movimento religioso, têm no mínimo parcialmente a sua razão na aceitação irrefletida da temporalidade da modernidade tardia como natural ou imutável. ${ }^{17}$

À forte tendência da nossa cultura de materialização, estetização e mercantilização do ser humano, responde-se com um fortíssimo acento na propagação da divinização ou da transformação e santificação instantânea do mesmo. Isso produz um novo tipo de alienação, o suposto super homem religioso que acredito pular "nas" e "através" das suas experiências religiosas intensas, as instâncias e os processos da vida e da vida religiosa comum. Podemos interpretar esta busca de experiências intensas e a crença na sua necessidade absoluta como a busca de repostas às demandas da aceleração do tempo. A tragédia anunciada é,

\footnotetext{
${ }^{17}$ Segundo a nossa percepção, isso leva a uma reavaliação das teses de Bittencourt Filho (2003). O atual sucesso da religião misticista não está no seu formato ou na sua ênfase, mas na sua não proximidade à temporalidade contemporânea, considerada natural. A sensação e a propagação, do inevitável sucesso dessa religiosidade, andam de carona com a suposta irreversível dinâmica dos "tempos modernos", a aceleração.
} 
porém, que os processos de amadurecimento e do discernimento dependem de desenvolvimento de laços afetivos e não do mero acumulo de emoções vivenciadas.

Mudou então a experiência humana? Certamente mudaram as condições da experimentação humana e, com elas, as formas humanas de responder a elas. Talvez seja exagerado dizer que hoje em dia o ser humano experimenta Deus totalmente diferente do que 2000 ou 500 anos atrás. No mínimo, parecem as formas paralelas indicar processos mais demorados que não se resumem simplesmente em um modelo de substituição radical.

Por outro lado, a aceleração do tempo levou o ser humano a uma reavaliação das preferências. As mais antigas formas aparentemente não se comunicam mais com tanta força. Novas formas caeem no gosto do povo, entre elas, a aceleração da experiência religiosa. Porém, até aqueles considerados "sucessos pós-modernos", enquanto instituições - de certo modo, em perspectiva pós-moderna, um anacronismo em si -, como algumas das igrejas neo-pentecostais, recorrem em seu simbolismo religioso aos exemplos antigos, culturalmente estabelecidos, como a lógica sacramental. Esta e outras observações fazem nos a concluir que a aceleração do tempo é somente um fator determinante na forma como seres humanos experimentam o sagrado, porém, um fator até agora subestimado.

\section{REFERÊNCIAS}

ATTALI, Jacques. Histoires du temps. Paris: Fayard, 1982.

AUGÉ, M. Não lugares: introdução a uma antropologia da super modernidade. Campinas, SP: Papirus, 1994.

BITTENCOURT FILHO, José. Matriz religiosa brasileira: religiosidade e mudança social. Petrópolis / Rio de Janeiro: Vozes / Koinonia, 2003. 260 p.

BRUNI, José Carlos. “O tempo da cultura em Nietzsche”. Ciência e Cultura, São Paulo, v. 54, n. 2, p. 31-35, out. 2002. 
CARRASCO, Davíd. Religions of Mesoamerica. 2. ed. Long Grove, Illinois: Waveland Press, Inc., 2014.

ELIAS, Norbert. Sobre o tempo. Rio de Janeiro: Jorge Zahar, 1998.

ELIAS, Norbert. Time: an essay. Tradução Edmund Jephcott. [S.l.]: Blackwell, 1990.

ELLIS, George F. R.; MAARTENS, Roy; MACCALLUM, Malcolm A. H. Relativistic

Cosmology. Cambridge: Cambridge University Press, 22 mar. 2012.

FLUSSER, Vilém. Do tempo e como ele acabará. São Paulo: OESP - Suplemento Literário, 1962.

FRANK, Adam. About time: from sun dials to quantum clocks - how the cosmos shapes our lives. Oxford: Oneworld Publications, 2012.

GARCIA, Vicente Romano. Ordem cultural e ordem natural do tempo. São Paulo: CISC - Centro Interdisciplinar de Semiótica, Cultura e Mídia, [s.d.]. Disponível em: < http://www.cisc.org.br/biblioteca/temporalidade.pdf >. Acesso em: 10 out. 2014.

GILBERT, Paul. Introdução à teologia medieval. Tradução de Dion Davi Macedo. São Paulo: Loyola, 1999. 156 p.

GLEICK, James. Faster: the acceleration of just about everything. [S.l.]: Pantheon, 1999, $336 \mathrm{p}$.

GLEICK, James. A velocidade da vida moderna: acelerado o desafio de lidar com o tempo. Rio de Janeiro: Campus, 2000.

JONSON, Bodil. Dez Considerações Sobre o Tempo. [ S.l]: José Olympio, 2004.

JUSTO, José Sterza. O “ficar" na adolescência e paradigmas de relacionamento amoroso da contemporaneidade. In: Revista do Departamento de Psicologia - UFF, v. 1, n. 1, p. 61-77, jan./jun. 2005.

KUHN, Thomas S. The copernican revolution: planetary astronomy in the development of western thought. Cambridge, Mass.: Harvard University Press, 1957.

KUHN, Thomas S. A revolução copernicana: a astronomia planetária no desenvolvimento do pensamento Ocidental. Lisboa: Edições 70, 1990.

KOYRÉ, Alexandre: The astronomical revolution: Copernicus-Kepler-Borelli. Ithaca, NY: Cornell University Press, 1973.

MEDEIROS, Beatriz; MONTEIRO, Marianna; MATSUMOTO, Roberta. Tempo e performance. Brasília: Ed. de pós-graduação em arte da Universidade de Brasília, 2007. 
NIETZSCHE, Friedrich. Kritische Studienausgabe. COLLI, Giorgio; MONTINARI, Mazzino (eds.). vol. 22. München/Berlin/New York: DTV de Gruyter, 1988. DTV/de Gruyter, 1988.

OLIVEIRA FILHO, Kepler de Souza; SARAIVA, Maria de Fátima Oliveira. Astronomia e astrofísica. Porto Alegre: Departamento de Astronomia - Instituto de Física Universidade Federal do Rio Grande do Sul, 2014.

PELBART, Peter Pál. O tempo não reconciliado. São Paulo: Perspectiva, 1998.

PELEGRINI, Milton. "As nossas imagens do tempo e como ele começou”. In: GhrebhRevista de Comunicação, Cultura e Teoria da Mídia, São Paulo, vol. 1, n. 1, p. 2020-229, out. 2002.

RECKWITZ, Andreas. Die Erfindung der Kreativität: zum Prozess gesellschaftlicher Ästhetisierung. Frankfurt am Main: Suhrkamp Verlag, 2012.

RIFKIN, Jermey. Uhrwerk Universum: die Zeit als Grundkonflikt des Menschen. [S.l.]: Droemer/Knaur, 1990.

ROSA, Hartmut. Beschleunigung. Frankfurt am Main: Suhrkamp, 2005.

ROSA, Hartmut. Beschleunigung und Entfremdung. Berlin: Suhrkamp, 2013.

ROSA, Hartmut. Weltbeziehungen im Zeitalter der Beschleunigung. Berlin: Suhrkamp, 2012.

SOUSA, Clarilza Prado de. Limites e possibilidades dos programas de aceleração de aprendizagem. Cadernos de Pesquisa, São Paulo, n. 108, p. 81-109, nov. 1999. Disponivel em: <http://www.scielo.br/pdf/cp/n108/a04n108.pdf>. Acesso em: 10 out. 2014. 